\title{
The comparison of projectile impact resistance of ultra-high-performance fibre-reinforced concrete with various aggregates
}

\author{
Martina Drdlová ${ }^{1 *}$ and Martin Šper ${ }^{2}$ \\ ${ }^{1}$ Research Institute for Building materials, Hnevkovskeho 65, Brno, Czech Republic \\ ${ }^{2}$ The Institute of Theoretical and Applied Mechanics of the Czech Academy of Sciences, Prosecka 79, \\ Praha, Czech Republic
}

\begin{abstract}
In order to apply the ultra-high-performance fibre-reinforced concrete (UHPFRC) in the constructions of ballistic protective structures, the impact resistance of UHPFRC has been investigated experimentally by conducting the high-speed projectile penetration tests. 5 mixtures with basalt and corundum aggregates with various grain size have been prepared and subjected to the quasi-static and $7.62 \times 54 \mathrm{R}$ B32 API projectile impact load using the striking velocity of $850 \mathrm{~m} / \mathrm{s}$. The influence of the strength, size and material of the aggregate on the projectile impact resistance represented by differential efficiency factor (DEF), structural integrity and area and height of impact crater has been evaluated. The superior projectile resistance of UHPFRC with corundum has been observed. Regarding the size of the aggregates, the incorporation of coarser aggregates brings better projectile impact resistance.
\end{abstract}

\section{Introduction}

During the lifespan, the structures may be exposed to several impact loading, such as car crash, blast or ballistic load. To increase the level of protection and defeat such intensive loadings, the UHPFRC is mainly used. This kind of concrete typically has extremely low water-binder-ratio, high amount of water reducer, high cement content and contains several admixtures as silica fume, micronized quartz, etc. UHPFRC, due to high compressive strength (more than $150 \mathrm{MPa}$ ) and tensile strength (20-50 MPa), high fracture energy (15-40 $\mathrm{kJ} / \mathrm{m}^{2}$ ) is very suitable for military applications, such as shelters, fortifications and other protective structures. The projectile impact resistance of common concrete is dependent on its compressive strength. For UHPFRC, this is not always valid and the projectile impact resistance cannot be simply inferred from the strength characteristics of the concrete. Other factors, as the amount of the aggregates and fibres, as well as the size and hardness of the aggregate influences the high-speed impact resistance [1-3]. Based on the results of projectile penetration tests, it was described in [4] and [5] that the depth of the penetration has not been decreasing after the compressive strength of the concrete reaches a certain value of about 150 $\mathrm{MPa}$.

*Corresponding author: drdlova@ vustah.cz 
UHPFRC with coarse aggregates usually provides lower compressive strength compared to UHPFRC with only fine aggregates. But even the compressive strength is decreased to some extent, the presence of the coarse aggregates can improve the projectile impact resistance. In Ref [6], the projectile impact penetration of basalt aggregated UHPFRC with the grain size between 5-15 mm has been tested. It was reported, that compressive strength, the fiber mixing fraction as well as coarse aggregates can help decrease the DOP of the projectile so as to enhance the impact resistance of the UHPFRC [6]. Regarding the fibres, the straight steel fibres in amount of $1.5-2 \%$ by volume has been reported as optimal dosage by $[6-8]$.

To expand the use of UHPFRC in constructions of protective structures, more data need to be obtained regarding the influence of the aggregate material and grain size on the resistance of the UHPFRC against projectile penetration. Already published studies have mainly been focused on HPC (high performance concrete) [9-11] and UHPFRC with the compressive strength bellow $180 \mathrm{MPa}$ [5,7,12-15]. The presented research has been conducted to assess the influence of the aggregate material and grain size on the projectile penetration of UHPFRC with compressive strength around $200 \mathrm{MPa}$ with the aim to formulate superior, cement based, projectile impact resistant material.

\section{Experimental}

\subsection{Materials}

For the composition of UHPFRC, the Portland cement Aalborg 52.5 R with low C3A content has been used. Silica fume Elkem $940 \mathrm{U}$ and milled quartz has been added to obtain the optimal packing density. The superplasticiser of the polycarboxylic type (Glenium ACE 446) has been used to achieve good workability of the mixture while keeping the low water/binder ratio $(0.25)$. Fine sand $(0-1 \mathrm{~mm})$ and two types of coarse aggregates have been used - basalt and corundum with grain size of 1-4 mm and 1-8 mm. Aggregates have been selected as to have similar shape index. $2 \%$ of steel fibres has been used as optimal based on the previous studies $[6,7]$.

Test samples for mechanical tests have been casted from 5 mixtures. The only variable in the mixture is the aggregate size and type - the samples designated as B and C contains basalt and corundum aggregates respectively. The number 4 and 8 indicates the $\mathrm{D}_{\max }(\mathrm{mm})$ of the aggregate. The R sample does not contain coarse aggregates, just the fine sand with the $D_{\max }$ of $1 \mathrm{~mm}$. Mixing procedure has been as follows: dry particles has been firstly mixed for about 2 minutes. Secondly, the water with superplascitizer have been added and mixed for 4 minutes. Finally, the steel fibres have been incorporated and mixed for another 2 minutes.

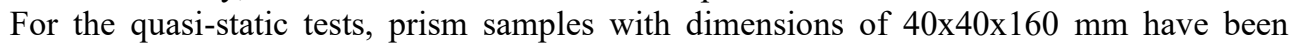
manufactured using the steel moulds and slight vibration. For the projectile impact test, cylindric samples with diameter $160 \mathrm{~mm}$ and thickness of $40 \mathrm{~mm}$ have been prepared by casting the material into the steel frames of thickness $6.8 \mathrm{~mm}$.

\subsection{Methods}

\subsubsection{Static tests}

The mechanical parameters have been obtained using universal strength testing machine TIRAtest 2710, R58/02. The compressive and flexural load (three-point flexural test) has been applied at quasi-static conditions (speed of $5 \mathrm{~mm} / \mathrm{min}$ ). Bulk density has also been 
determined. Both strength tests and bulk density determination have been performed according to the standard ČSN EN 12390-3.

\subsubsection{Projectile penetration tests}

The depth of penetration test (DOP) has been conducted as per the configuration in Fig. 1. The cylindrical sample with bulk density $\rho_{\mathrm{s}}$ and thickness $H_{\mathrm{s}}$ has been placed before the aluminium alloy backing material with bulk density $\rho_{\mathrm{r}}$ and fixed on the firing stand. The fixed sample has been subjected to the impact of the 7.62 AP projectile at the velocity about $850 \mathrm{~m} / \mathrm{s}$. Penetration into the backing material $\left(\mathrm{P}_{\mathrm{res}}\right)$ has been evaluated via X-ray analysis.

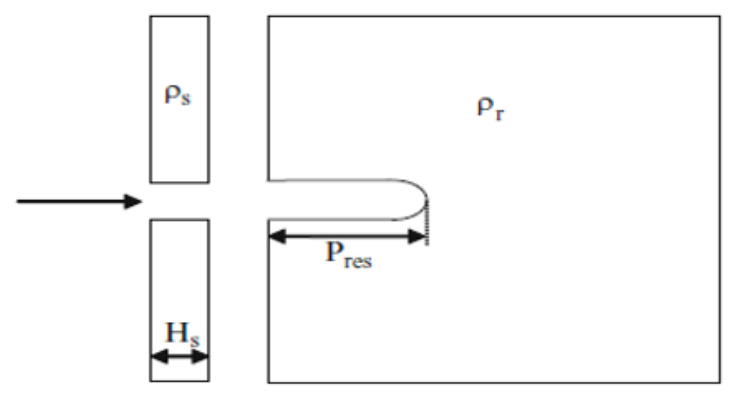

Fig. 1 Schematic of the DOP test

The ballistic efficiencies of each sample have been expressed by the differential efficiency factor (DEF) calculated according to the following equation:

$D E F=\frac{\rho_{r}\left(P_{r}-P_{r e s}\right)}{\rho_{s} H_{s}}$

In total, 50 samples have been tested. Additionally, the depth and area of the impact crater have been measured.

\subsection{Results and discussion}

\subsubsection{Static tests results}

The results of determined mechanical properties at quasistatic load are summarized in Table 1. The average value of the results of 6 flexural strength tests and 12 compressive strength tests for each mixture is given in the Table. The rising of the aggregate size reduces the compressive strength, but not to high extent; the basalt aggregated samples with $\mathrm{D}_{\max }=4$ and $8 \mathrm{~mm}$ exhibited the compressive strength of 202.0 and $189.1 \mathrm{MPa}$, respectively. The same trend has been observed in case of corundum aggregated samples - the compressive strengths for specimens with $\mathrm{D}_{\max }=4$ and $8 \mathrm{~mm}$ has been measured 217.4 and $204 \mathrm{MPa}$. Those findings correspond with the UHPFRC technology, but contradict the findings published by [1] or [16] reporting the opposite trend for basalt, granite and corundum aggregated UHPFRC. Regarding the flexural strength, similar values for all mixtures has been measured, being in range 37.0-38.9 MPa. Higher compressive strength of corundum-based UHPFRC to basaltbased UHPFRC has been observed, which indicates that the compressive strength of the UHPFRC increases with rising hardness/strength of the coarse aggregates. The same trends have been observed and reported by [1]. 
Table 1. Physico-mechanical properties of the tested UHPFRC mixtures

\begin{tabular}{|l|c|c|c|c|}
\hline Des. & $\begin{array}{c}\text { Aggregate } \\
\text { material/max grain } \\
\text { size }(\mathrm{mm})\end{array}$ & $\begin{array}{c}\text { Bulk } \\
\text { density } \\
\left(\mathrm{kg} \cdot \mathrm{m}^{-3}\right)\end{array}$ & $\begin{array}{c}\text { Compressive } \\
\text { strength } \\
(\mathrm{MPa})\end{array}$ & $\begin{array}{c}\text { Flexural } \\
\text { strength } \\
(\mathrm{MPa})\end{array}$ \\
\hline B 4 & basalt/4 & 2644 & 202.0 & 37.0 \\
\hline B 8 & basalt/8 & 2675 & 189.1 & 38.3 \\
\hline C 4 & corundum/4 & 2929 & 217.4 & 38.9 \\
\hline C 8 & corundum/8 & 2920 & 204.1 & 37.2 \\
\hline R & no coarse aggregate & 2720 & 205.1 & 38.7 \\
\hline
\end{tabular}

\subsubsection{Projectile penetration test results}

The given values are average of 10 measurements. The firing stand with attached target is depicted in Fig. 2. Level of damage of the front (impacted) side of the test samples view the photographs in Fig. 3 and 4. No visible cracks has emerged on the rear faces of the samples. The projectile penetration into the test sample always creates the impact crater followed by tunnel with the diameter nearly same as the projectile diameter. The crater depth has been measured using the calliper. The area of the impact crater at the top of the sample has been determined using the J-image program and expressed in $\mathrm{mm}^{2}$. Fig. 3 (right) shows the X-ray photography of backing witness cylinder with marked penetration depth $\left(\mathrm{P}_{\text {res }}\right)$. The $\mathrm{P}_{\text {res }}$ (evaluated via X-ray analysis), the depth and area of the impact crater, as well as the calculated values of the DEF are summarized in Table 2.
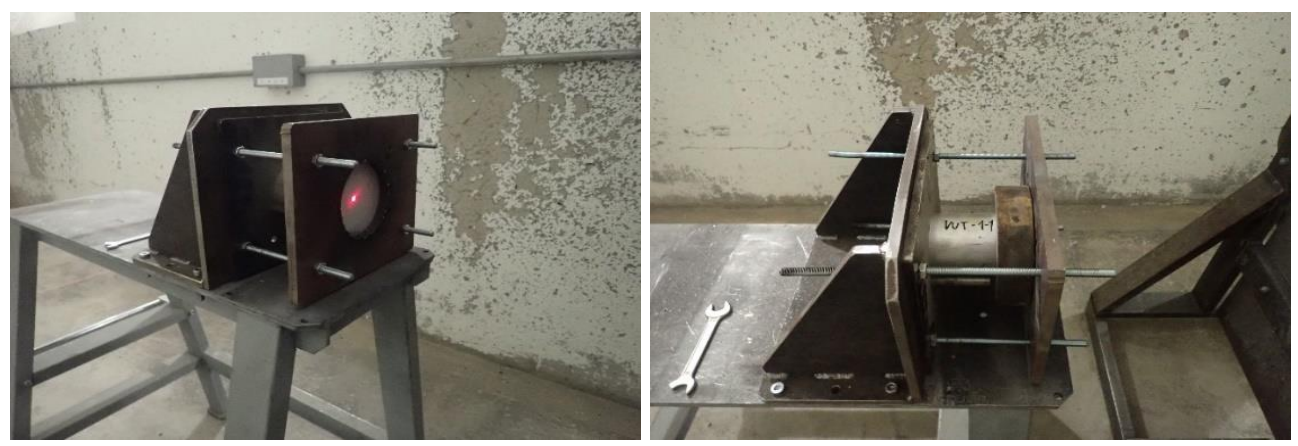

Fig. 2 Firing stand with test target

Table 2. Results of projectile penetration tests

\begin{tabular}{|l|c|c|c|c|}
\hline Des. & Pres & $\begin{array}{c}\text { Depth of } \\
\text { the crater } \\
(\mathrm{mm})\end{array}$ & $\begin{array}{c}\text { Area of } \\
\text { impact crater } \\
\left(\mathrm{mm}^{2}\right)\end{array}$ & DEF (-) \\
\hline B 4 & 21.2 & 18.23 & 6648 & 0.644 \\
\hline B 8 & 18.1 & 18.1 & 6712 & 0.689 \\
\hline C 4 & 6.8 & 16.9 & 4221 & 0.869 \\
\hline C 8 & 5.1 & 16.89 & 4324 & 0.906 \\
\hline R & 22.1 & 18.9 & 3125 & 0.641 \\
\hline
\end{tabular}


The sample without coarse aggregates $(R)$ and basalt aggregated sample with $D_{\max }=4 \mathrm{~mm}$ (B4) show similar values of $\mathrm{P}_{\text {res }}$ and $\mathrm{DEF}$, with slightly better results in case of $\mathrm{B} 4$ sample. Also, the crater depth is similar in both cases. The addition of the coarse aggregate of standard strength/hardness to the high-strength matrix does not seem to be highly beneficial for improvement of the ballistic performance of UHPFRC. Additionally, significantly larger impact crater area has been observed in case of B4 UHPFRC compared to R. This can be attributed to more homogenous structure of the mixture without coarse aggregates with more uniform fibre distribution as well as the slight bleeding of the mixtures with coarse aggregates. As the consequence of the bleeding, the thin layer of fragile unreinforced matrix without fibres has been created, more prone to the damage. Comparing the basalt aggregated UHPFRC with Dmax $=4 \mathrm{~mm}$ and $8 \mathrm{~mm}$, better penetration impact resistance has been observed in case of the sample with higher $\mathrm{D}_{\max }(\mathrm{B} 8)$, even though its compressive strength at quasistatic load has been lower. The same trend has been observed in the case of corundum aggregated samples. Therefore, the projectile impact resistance cannot be simply inferred from compressive strength of the UHPFRC, even though some studies reported that increasing the compressive strength helps decreasing DOP and thus projectile impact resistance of the high-performance concretes [2,17].
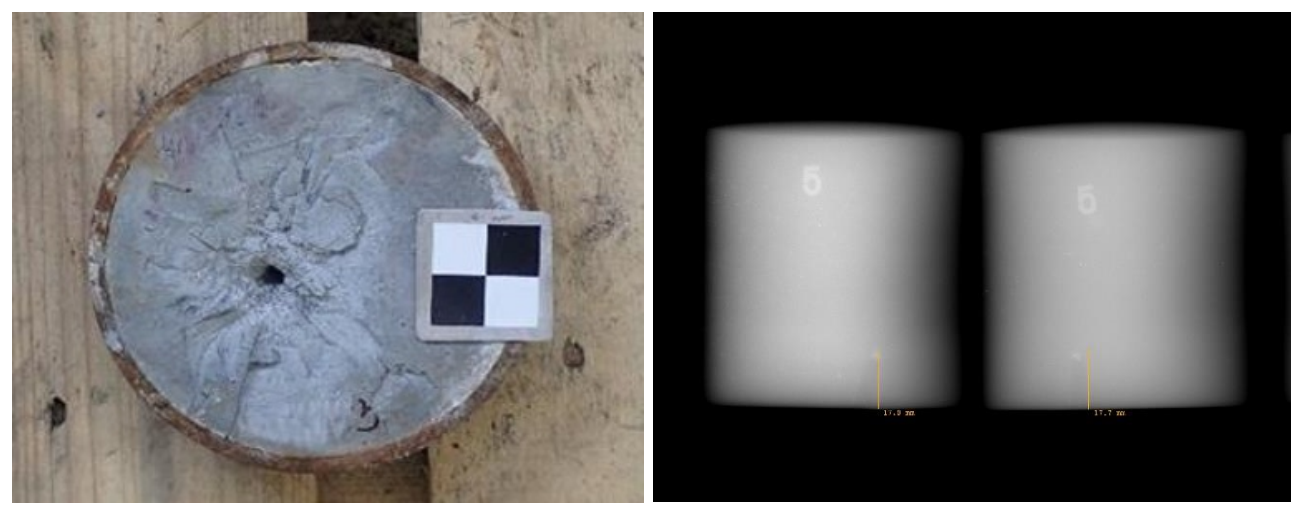

Fig. 3 Test sample $\mathrm{R}-3$ after the projectile penetration test (left) and X-ray photo of backing "witness" cylinder with the marked depth of penetration of the projectile

Comparing the ballistic performance of basalt and corundum aggregated UHPFRC, significantly better results have been achieved in case of UHPFRC with corundum. The DEF of the sample C8 (corundum based) and B8 (basalt based) has been calculated 0.906 and 0.689 , respectively. DEF characteristics considers the different bulk density of basalt-and corundum-based mixtures and thus enables to compare the efficiency of the particular aggregate in rising the ballistic resistance of the UHPFRC. The clear influence of the coarse aggregates strength/hardness on the DEF values can be derived. Hard coarse aggregate can reduce $\mathrm{P}_{\text {res }}$ by aggravating the mass abrasion of the projectile and reduce the penetration efficiency [1].
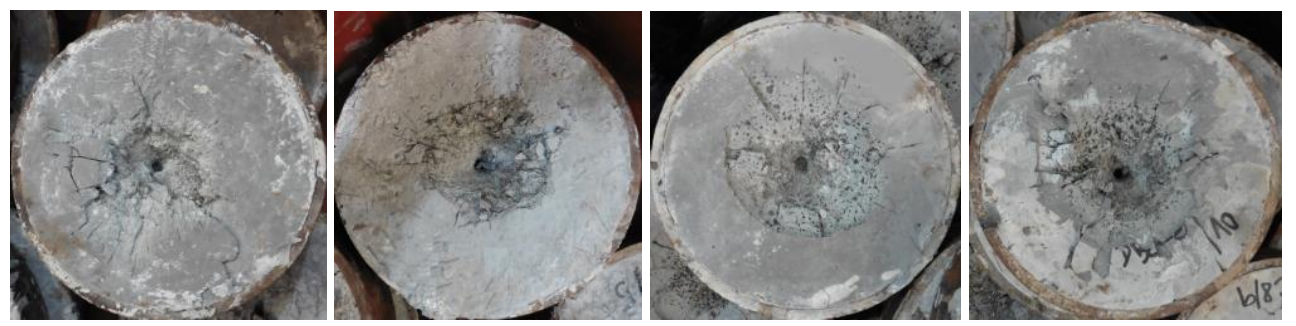

Fig. 4 Front surface of the targets after projectile penetration test; from the left C4, C8, B4, B8 
Regarding the size of the aggregate, with rising $D_{\max }$, the DEF increases for both types of UHPFRC. This coincides with the conclusions drawn by [1] and [2] and is connected with the fact, that aggregate size enlarging increases the probability that the projectile strikes the aggregate. On the other hand, even though the results of ballistic test of C8 have shown better overall results of DEF compared to $\mathrm{C} 4$, due to test configuration (4 cm thick targets), higher scatter of the results due to lower homogeneity of the material has been observed. This must be considered while designing the protective structures - the size of the aggregates must correspond to the mass of the construction, which must be sufficient enough to be considered homogenous.

\section{Conclusions}

The impact resistance of basalt and corundum based UHPFRC with the compressive strength around $200 \mathrm{MPa}$ has been investigated experimentally by conducting the high-speed projectile penetration tests. To evaluate the connection between compressive/flexural strength of the material and its projectile penetration resistance, the quasistatic mechanical tests has been performed as well. The following conclusions can be drawn:

-The quasistatic compressive strength of the UHPFRC is improved by increasing the strength (hardness) of the coarse aggregate. The rising $D_{\max }$ slightly reduces the compressive strength of both corundum and basalt aggregated UHPFRC.

-Corundum based UHPFRC shows significantly better projectile penetration resistance in terms of DEF, crater area and depth, compared to basalt based UHPFRC.

- The addition of the coarse aggregate of standard hardness to the high-strength matrix does not seem to be highly beneficial for improvement of the ballistic performance of UHPFRC.

-The ballistic resistance cannot be simply inferred from the compressive strength of the UHPFRC material. The ballistic performance of UHPFRC is mainly influenced by the hardness and size of the coarse aggregate. Larger sized coarse aggregates can help reducing the $\mathrm{P}_{\text {res }}$ and increasing the $\mathrm{DEF}$, but the quality of the used aggregate, in particular its hardness, has a decisive influence on the ballistic resistance of the UHPFRC - using the corundum aggregate instead of basalt, the $34.9 \%$ increase of DEF has been observed.

Further work will be focused on the FEM modelling of the corundum based UHPFRC elements for protective structures.

\section{Acknowledgement}

The authors wish to express their gratitude and sincere appreciation to the authority of The Technology Agency of the Czech Republic, project No. FW01010021 for financial support.

\section{References}

[1] H. Wu, q. Fang, J. Gong, J.Z. Liu, J.H. Zhang, Z.M. Gong Projectile impact resistance of corundum aggregated UHP-SFRC International Journal of Impact Engineering, 84 (2015), pp. 38-53

[2] M.H. Zhang, V.P.W. Shim, G. Lu, C.W. Chew Resistance of high-strength concrete to projectile impact Int J Impact Eng, 31 (7) (2005), pp. 825-841

[3] A.N. Dancygier, D.Z. Yankelevsky, C. Haegermann Response of high-performance concrete plates to impact of non- deforming projectiles Int J Impact Eng, 34 (11) (2007), pp. $1768-1779$ 
[4] H. Langberg, G. Markeset High performance concrete-penetration resistance and material development Proceedings of the ninth international symposium on interaction of the effects of munitions with structures, Berlin-Strausberg (1999), pp. 933-941

[5] H. Wu, Q. Fang, X.W. Chen, Z.M. Gong, J.Z. Liu Projectile penetration of ultra-highperformance cement-based composites at $510 \mathrm{~m} / \mathrm{s}$ to $1320 \mathrm{~m} / \mathrm{s}$ Constr Build Mater, 74 (15) (2015), pp. 188-200

[6] H. Wu, Q. Fang, X.W. Chen, Z.M. Gong, J.Z. Liu Projectile penetration of ultra-highperformance cement-based composites at $510 \mathrm{~m} / \mathrm{s}$ to $1320 \mathrm{~m} / \mathrm{s}$ Constr Build Mater, 74 (15) (2015), pp. 188-200

[7] P. Máca, R. Sovják, P. Konvalinka Mix design of UHPFRC and its response to projectile impact Int J Impact Eng, 63 (5) (2010), pp. 158-163

[9] M.H. Zhang, M.S.H. Sharif, G. Lu Impact resistance of high-strength fibre-reinforced concrete Mag Concr Res, 59 (3) (2007), pp. 199-210

[10] R.C. Liu, B. Wu, X.Z. Zhang, G.S. Shen, X.L. Niu Tests on resisting projectiles penetration of high strength volume steel fiber concrete Chin J Explos Shock Waves, 22 (4) (2002), pp. 368-372

[11] X. Luo, W. Sun, Y.N. Sammy Chan Characteristics of high-performance steel fiberreinforced concrete subject to high velocity impact Cem Concr Res, 30 (6) (2000), pp. 907914

[12] Liu, $\mathrm{J}$ at al. Experimental and numerical studies of ultra-high performance concrete targets against high-velocity projectile impacts, Engineering Structures 1732018 166-179

[13] Lampropoulos A, Paschalis SA, Tsioulou O, Dritsos SE. Strengthening of reinforced concrete beams using ultra high-performance fibre reinforced concrete (UHPFRC). Eng Struct 2016;106:370-84.

[14] Ng KW, Garder J, Sritharan S. Investigation of ultra high performance concrete piles for integral abutment bridges. Eng Struct 2015;105:220-30

[15] Feng J, Sun W, Liu Z, Cui C, Wang X. An armour-piercing projectile penetration in a double-layered target of ultra-high-performance fiber reinforced concrete and armour steel: experimental and numerical analyses. Mater Des 2016;102:131-41

[16] W.H. Zhang Investigation of microstructure formation mechanism and dynamic mechanical behavior of UHPCC Southeast University, Nanjing, China (May 2010), pp. 95103 [Doctoral thesis]

[17] E.F. O'Neil, B.D. Neeley, J.D. Cargile Tensile properties of very-high-strength concrete for penetration-resistant structures Shock Vib, 6 (5-6) (1999), pp. 237-245 